\title{
Degradación de oxalato por bacterias oxalotróficas asociadas a plantas del género Oxalis sp en regiones Andinas del departamento de Nariño, Colombia
}

\author{
Oxalate degradation by oxalotrophic bacteria associated with plants of the genus Oxalis sp in the Andean region \\ of the department of Nariño, Colombia
}

Roger David Castillo-Arteaga1', Edith Mariela Burbano-Rosero², Iván Darío Otero-Ramirez³, Pablo Fernández-Izquierdo4

1 MSc (c) Microbiología. Laboratório de Bioproductos, Instituto de Ciências Biomédicas, Universidade de São Paulo. São Paulo, Brasil. e-mail: rogerdavyd@usp.br

2 PhD Microbiología. Profesora asociada, Departamento de Biología, Universidad de Nariño. Pasto, Colombia. e-mail: marielaburbano@gmail.com

3 MSc (c) Microbiología Agroindustrial, Grupo de Investigación en aprovechamiento de subproductos agroindustriales, Facultad de Ciencias Agrarias, Universidad del Cauca. Popayán, Colombia. e-mail: ivanda@unicauca.edu.co

4 PhD Microbiología. Profesor asociado, Departamento de Biología, Universidad de Nariño, Pasto, Colombia. e-mail: pabfdez@gmail.com

\section{Resumen}

Introducción: El ácido oxálico $\left(\mathrm{H}_{2} \mathrm{C}_{2} \mathrm{O}_{4}\right)$ y las sales de oxalato son sustancias altamente oxidadas y consideradas tóxicas para algunos sistemas biológicos, incluido el humano, no obstante, pueden ser utilizadas como fuente de carbono y energía por algunas comunidades bacterianas, denominadas oxalotróficas, las cuales por su capacidad metabólica forman parte de la ruta biogeoquímica oxalato-carbonato (OCP, oxalate-carbonate pathway). Objetivo: Aislar y caracterizar bacterias oxalotróficas a partir de plantas del género Oxalis sp., de zonas alto-andina de NariñoColombia. Materiales y métodos: Se recolectaron muestras de suelo rizosférico de plantas oxalogénicas que fueron analizadas con parámetros fisicoquímicos y se utilizó un medio selectivo Schlegel para el aislamiento de bacterias oxalotróficas. Resultados: Las bacterias aisladas en medio selectivo Schlegel fueron caracterizadas bioquímicamente como: (Serratia fonticola, Bacillus amyloliquefaciens, Bacillus subtilis, Bacillus vallismortis y Bacillus cereus). Estas especies fueron capaces de degradar oxalato e incrementar el pH producto de la degradación. Conclusión: Este tipo de bacterias pueden ser estudiadas en trabajos complementarios para evaluar su potencial como biofertilizantes y/o alternativas de bioremediación en suelos ácidos. El estudio a pesar de ser indicativo a nivel biológico, puede en un futuro y con base en mayores soportes en investigación, tornarse en una promisoria aplicación para reducir el oxalato de calcio en los alimentos de consumo diario que presentan un renglón de importancia agrícola en la región, potencialmente dañinos para la función renal.

Palabras clave: Oxalato de calcio; Oxalis sp; degradación biológica; cálculos renales. (Fuente: DeCS, Bireme). 


\begin{abstract}
Introduction: Oxalic acid $\left(\mathrm{H}_{2} \mathrm{C}_{2} \mathrm{O}_{4}\right)$ and oxalate salts are highly oxidized substances, which are considered as toxic for some biological systems, including the human being; however, they can be used as a source of carbon and energy for some bacterial communities called oxalotrophic which are part of the so called oxalate-carbonate geochemistry pathway (OCP) due to its metabolic capacity. Objective: The aim of this research was to isolate and characterize oxalotrophic bacteria from plants of the genus Oxalis sp. in the high-andean zone of the department of Nariño, Colombia. Materials and methods: Samples of rhizosphere soil from oxalogenic plants were analyzed with physicochemical parameters and a Schlegel selective medium was used to isolate oxalotrophic bacteria. Results: The isolated bacteria through Schlegel selective medium were identified biochemically as: (Serratia fonticola, Bacillus amyloliquefaciens, Bacillus subtilis, Bacillus vallismortis and Bacillus cereus). The identified species play an important role in the rhizosphere soil, principally for the capacity to increase the $\mathrm{pH}$ during oxalate consumption. Conclusion: This type of bacteria can be studied in additional studies to evaluate their potential as bio-fertilizers and/or bioremediation alternatives in acid soils. Despite that the study is indicative at a biological level, it can become a promising application, in the future and with greater support in research, to reduce the calcium oxalate in food of daily consumption which represent an agricultural important line in the region and are potentially harmful to kidney finction.
\end{abstract}

Keywords: Calcium oxalate; Oxalis sp; biological degradation; kidney stones. (Source: DeCS, Bireme).

\section{Introducción}

El flujo de nutrientes en los ecosistemas, está determinada por la interacción de los organismos vivos, las condiciones ambientales y la disponibilidad de los nutrientes en diferentes formas químicas.1 Actualmente se conoce que, el desequilibrio de carbono formado en la biosfera desencadena respuestas biológicas que impactan de manera negativa en los ecosistemas. Es de resaltar, que la principal vía de respuesta en los organismos vegetales al exceso de $\mathrm{CO}_{2}$, es el incremento en el metabolismo fotosintético, que induce diferentes respuestas fisiológicas y bioquímicas, como el incremento de la biomasa vegetal o generación de mayor concentración de exudados tri o dicarboxílicos a través de las raíces como una vía de detoxificación por exceso de compuestos carbonados.2-4

Entre los ácidos dicarboxílicos secretados por las plantas y de mayor trascendencia, se encuentra el ácido oxálico, el cual se acumula en las plantas como producto final del metabolismo del ciclo de Calvin. Este proceso se da en células vegetales especializadas denominadas glomeroblastos que participan en la síntesis, transporte y transformación del ácido distribuyéndolo en diferentes tejidos vegetales o liberándolo por el sistema radicular después de su respectiva transformación a sal de oxalato de sodio, u oxalato de calcio.5-7. Enormes cantidades de oxalato se forman en la biosfera a partir de plantas, hasta el momento, se ha establecido que 150 taxas vegetales producen este compuesto 8, especialmente en plantas de la familia Oxalidaceae.6,7,9-13

La ruta de oxalato-carbonato es un proceso natural biogeoquímico involucrado en la captura de carbono atmosférico e incluye la interacción de plantas y microorganismos.14 Muchos grupos taxonómicos de bacterias pueden utilizar oxalato como única fuente de carbono a través de la degradación de oxalato de calcio, que en consecuencia conduce a la precipitación de CaCO.3,15 El grupo de bacterias oxalotróficas descrito es amplio, e incluye bacterias Gramnegativas (Alfa-, Beta- y Gammaproteobacteria) y bacterias Gram-positivas (Firmicutes y Actinobacteria).16 Las bacterias oxalotróficas son descritas como las principales oxidantes de oxalato de calcio y métodos de cultivo convencionales pueden revelar un conjunto diverso de bacterias oxalotróficas que viven cerca de la rizosfera de los bosques tropicales.14,17

El ácido oxálico liberado al suelo, puede estar en forma soluble como insoluble. Cuando el pH es neutro el ácido oxálico se combina con sodio o potasio formando sales solubles, de lo contrario se forman sales insolubles, compuestos más 
comunes, con elementos como calcio, y en menor cantidad con magnesio o hierro.18 En grandes cantidades el ácido oxálico es tóxico debido a sus propiedades quelantes y de interacción con metales pesados como el $\mathrm{Pb}$. Cuando existe vertimiento de ácidos sobre el suelo, provoca un drástico aumento de la fracción soluble y/o intercambiable de $\mathrm{Pb}$ ( $>37 \%$ con respecto al contenido total de $\mathrm{Pb}$ ).19 La acidificación del suelo conlleva a que se pierdan cationes alcalinos y alcalinotérreos $\left(\mathrm{K}^{+}, \mathrm{Na}^{+}, \mathrm{Ca}^{+2}, \mathrm{Mg}^{+2}\right)$ y el incremento concomitante de cationes metálicos $\left(\mathrm{Al}+3, \mathrm{Fe}^{+3}, \mathrm{Mn}^{+3}\right)$ puede ocasionar hidrolisis acida. Esta hidrólisis produce en el suelo un cambio de pH que puede llegar a 4,2.20

En busca de una solución, recientemente se ha mostrado la alta actividad de la microbiota en los suelos tropicales vinculada a la variedad de metabolismos que presentan los microorganismos, lo que contribuye al ciclaje de nutrientes; dicha microbiota está implicada en el consumo y bioconversion de los mismos.21 Es de resaltar, que varios grupos taxonómicos de bacterias utilizan el oxalato como fuente de carbono, estas bacterias son denominadas como oxalotróficas y están directamente relacionadas con el ciclo OCP como un mecanismo captación de carbono.5,15

Disponer de este tipo de bacterias puede tener una aplicabilidad en la biofertilización y/o bioremediación de suelos, debido a la eventual disminución de formas toxicas solubles con metales pesados y a su vez, al aumento de cationes de intercambio $\left(\mathrm{K}^{+}, \mathrm{Na}^{+}, \mathrm{Ca}^{+2}, \mathrm{Mg}^{+2}\right)$, que normalmente no están disponibles para los organismos cuando hay exceso de ácidos orgánicos.

Este estudio tuvo como objetivo aislar, identificar y evaluar la capacidad oxalotrófica de bacterias asociadas a suelo rizosférico de plantas del genero Oxalis recolectadas de dos regiones del departamento de Nariño (Chimayoy y Catambuco), Colombia. Las bacterias oxalotróficas aisladas se identificaron por medio de pruebas bioquímicas, y adicionalmente se verificó la degradación de oxalato in vitro bajo las condiciones de $\mathrm{pH}$ que fueron observadas en el suelo donde se las aisló.

\section{Materiales y métodos}

Recolección de material biológico y zona de muestreo. Ejemplares de las especies Oxalis

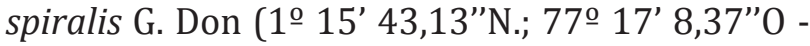
2752 m.sn.m) y Oxalis tuberosa Molina (1윽' 29,17'N.; 77잉 15,86" 0), previamente reportadas como productoras de ácido oxálico fueron recolectadas en dos zonas de la región andina del departamento de Nariño-Colombia. Las regiones seleccionadas fueron Chimayoy y Catambuco, la primera localizada a $4 \mathrm{Km}$ de la vía que comunica a San Juan de Pasto con el interior de Colombia, Corregimiento Morasurco a una altura de 2.700 metros sobre el nivel del mar y la segunda localizada hacia el suroeste, aproximadamente a unos ocho kilómetros del centro de San Juan de Pasto, con una altura promedio sobre el nivel del mar de 2.700 metros.

Se documentó las plantas recolectadas y la presencia de semillas, como también se tomó en cuenta, el estado de maduración del individuo.22,23 Además, se recolectaron muestras por triplicado de suelo rizosférico a $20 \mathrm{~cm}$ alrededor de las raíces, este último procedimiento siguió la metodología propuesta por Somasegaran y Hoben, 1985.24 Las muestras fueron transportadas en bolsas estériles, para el aislamiento de bacterias oxalotróficas y su análisis fisicoquímico (Tabla 1).

Tabla 1. Parámetros fisicoquímicos evaluados y métodos aplicados para la determinación de los parámetros fisicoquímicos asociados al suelo rizosférico de las plantas 0 . spiralis y 0 . tuberosa

\begin{tabular}{lll}
\hline \multicolumn{1}{c}{ Parámetro } & \multicolumn{1}{c}{ Método } & \multicolumn{1}{c}{ Técnica } \\
\hline $\begin{array}{l}\text { pH suelo: } \mathrm{H}_{2} \mathrm{O} \\
\text { Materia } \\
\text { orgánica (MO) }\end{array}$ & NTC 5264 & Potenciométrica \\
& Walkley-Black & $\begin{array}{l}\text { Espectrofotométrica } \\
\text { UV-Vis }\end{array}$ \\
$\begin{array}{l}\text { Nitrógeno total } \\
\left(\mathrm{N}_{\mathrm{t}}\right)\end{array}$ & $\begin{array}{l}\text { Con base en } \\
\text { materia orgánica } \\
\left(\mathrm{P}_{\mathrm{D})}\right.\end{array}$ & Cálculo \\
& Bray II y Kurtz & $\begin{array}{l}\text { Espectrofotométrica } \\
\text { UV-Vis }\end{array}$ \\
$\begin{array}{l}\text { Ca, Mg y K de } \\
\text { cambio }\end{array}$ & $\mathrm{CH}_{3} \mathrm{COONH}_{4} 1 \mathrm{~N}$ & $\begin{array}{l}\text { Espectrofotometría de } \\
\text { absorción atómica }\end{array}$ \\
\hline
\end{tabular}


Enriquecimiento selectivo y aislamiento de bacterias oxalotróficas. El enriquecimiento se realizó en medio líquido Schlegel AB $(250 \mathrm{~mL}), 25$ modificado para el aislamiento de bacterias oxalotróficas. Periódicamente se realizó observación de zonas claras que evidencian el consumo de oxalato por los microorganismos presentes en el medio.15 Para ello, se adicionaron $4 \mathrm{~g}$ de oxalato de calcio como única fuente de carbono. La elección de la sal de oxalato se realizó de acuerdo con los rendimientos energéticos reportados por Bravo y Colaboradores, 2011.22 La fuente de nitrógeno consistió en $\mathrm{NH}_{4} \mathrm{Cl}$ en relación 1:4 a la fuente de carbono. El medio fue inoculado con $1 \mathrm{~g}$ de suelo rizosférico e incubado en Shaker a $30^{\circ} \mathrm{C}$ y $100 \mathrm{rpm}$. Periódicamente, se realizó evaluación de crecimiento y la observación de halos que evidencian el consumo de oxalato por los microorganismos presentes en el medio. Las colonias que presentaron halo de degradación de oxalato fueron seleccionadas y conservadas a $4^{\circ} \mathrm{C}$ en glicerol al $30 \%$.

Caracterización bioquímica de bacterias oxalotróficas. La caracterización bioquímica se realizó de acuerdo a las pruebas establecidas en el manual de Bergey's,26 incluyeron Indol, Sulfuros, Catalasa, Oxidasa, Voges Proskauer, Citrato Simmons, crecimiento desde $4^{\circ} \mathrm{C}$ a $65^{\circ} \mathrm{C}$, crecimiento desde $2 \%$ a $10 \%$ de $\mathrm{NaCl}, \mathrm{pH}$ entre 3 y 8 como también uso de los carbohidratos glucosa, sacarosa, fructosa, maltosa, galactosa, xilosa y ramnosa. Complementariamente, se evaluaron características microscópicas como posición de esporas y motilidad.

Degradación de oxalato por bacterias oxalotróficas. La degradación de oxalato fue determinada siguiendo la metodología propuesta por Blackmore y Quayle.27 Cada aislado bacteriano se inoculó por triplicado en $60 \mathrm{~mL}$ de caldo Schlegel modificado con los valores de $\mathrm{pH}$ obtenidos en el suelo de cada planta. Las suspensiones celulares se incubaron a $30^{\circ} \mathrm{C}$ y 100 rpm durante 4 días por intervalos de 24 horas y realizando lecturas de $\mathrm{pH}$ y degradación de oxalato por titulación. Para esto, $3 \mathrm{~mL}$ del medio de cultivo se mezclaron con $1 \mathrm{~mL}$ de ácido sulfúrico $2 \mathrm{~N}$ y se llevaron a baño maría a $60^{\circ} \mathrm{C}$, posteriormente se tituló con una solución de permanganato de sodio $0,1 \mathrm{~N}$. El consumo de oxalato se calculó por estequiometria de reactantes y productos.

\section{Análisis de datos}

Para el análisis del ensayo de consumo de oxalato, la desviación estándar se calculó sobre la base de tres réplicas independientes. Se aplicó un test T para evaluar si hay diferencias significativas. Usando los datos referentes al comportamiento de los microorganismos con respecto a su perfil bioquímico, se construyó un dendrograma con el método de neighbor-joining usando la matriz de presencia-ausencia (1-0) en el software PAST versión. 2.15.

\section{Resultados}

Análisis de parámetros fisicoquímicos del suelo rizosférico. El análisis de suelo indicó que las especies $O$. spiralis y 0 . tuberosa se encuentran en suelos ácidos, debido a que el pH fue de 4,9 y 5,4 , respectivamente (Tabla 2).

Tabla 2. Parámetros fisicoquímicos de suelo rizosférico de las especies Oxalis spiralis y Oxalis tuberosa

\begin{tabular}{|c|c|c|c|}
\hline Parámetro & $\begin{array}{c}\text { Unidad } \\
\text { de } \\
\text { Medida }\end{array}$ & $\begin{array}{c}\text { Oxalis } \\
\text { spiralis }\end{array}$ & $\begin{array}{c}\text { Oxalis } \\
\text { tuberosa }\end{array}$ \\
\hline $\begin{array}{ll}\text { PH suelo: } \mathrm{H}_{2} \mathrm{O} & 1: 1\end{array}$ & & 4,9 & 5,4 \\
\hline Materia orgánica (MO) & $\%$ & 20 & 17,39 \\
\hline Nitrógeno total $\left(\mathrm{N}_{\mathrm{t}}\right)$ & $\%$ & 0,67 & 0,61 \\
\hline $\mathrm{P}$ disponible & $\mathrm{mg} / \mathrm{Kg}$ & 64,15 & 36,08 \\
\hline $\mathrm{Ca}^{2+}$ & $\begin{array}{r}\mathrm{Cmol} \\
\text { carga/Kg }\end{array}$ & 5,75 & 20 \\
\hline $\mathrm{Mg}^{2+}$ & $\begin{array}{r}\mathrm{Cmol} \\
\mathrm{carga} / \mathrm{Kg}\end{array}$ & 0,81 & 6,02 \\
\hline $\mathrm{K}^{+}$ & $\begin{array}{r}\mathrm{Cmol} \\
\text { carga } / \mathrm{Kg}\end{array}$ & 0,14 & 2,49 \\
\hline
\end{tabular}

Aislamiento selectivo de bacterias oxalotróficas. En este estudio se obtuvo un total de 34 aislados, de las cuales siete presentaron halos claros y definidos en medio Schlegel AB con oxalato de calcio, como única fuente de carbono, (Tabla 3). Seis de los aislados correspondieron a bacterias Gram positivas y un aislado fue Gram negativo; el tiempo de crecimiento promedio fue de 12 días, lo que coincide con las observaciones realizadas por Bravo y colaboradores en el año 2011.22 


\section{Caracterización bioquímica}

La caracterización bioquímica permitió identificar los aislados como: (Serratia fonticola, Bacillus amyloliquefaciens, Bacillus subtilis, Bacillus vallismortis y Bacillus cereus). El rango de temperatura óptimo de crecimiento para todos los aislados fue de 30 a $42^{\circ} \mathrm{C}$, de igual manera se observó crecimiento en un medio con $2 \%$ de $\mathrm{NaCl}$, observaciones que concuerdan con otros géneros de oxalótrofos.16 Condiciones ambientales similares se presentan en suelos rizosféricos, donde los metabolitos secundarios exudados a traves de la raiz, proporcionan una fuente abundante de carbono aprovechada por los microorganismos de suelo que hacen parte del complejo.

El dendrograma generado usando los datos referentes al comportamiento de los microorganismos con respecto a su perfil bioquímico permitió observar la similaridad presentada entre los diferentes aislados bacterianos oxalotróficos a partir de 0 . tuberosa y o. spiralis, compartiendo aproximadamente un $72 \%$ de similaridad entre todos los aislados (Figura 1).

Figura 1. Dendrograma de relación bioquímica entre aislados de bacterias oxalotróficas a partir de 0 . tuberosa y 0 . spiralis

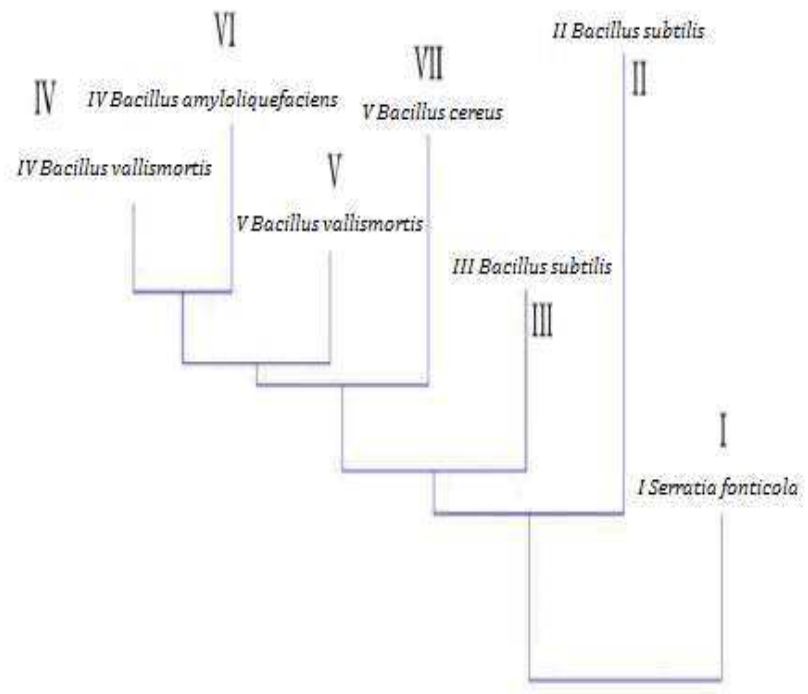

\section{Degradación de oxalato}

Todos los aislados se inocularon en un reactor con una concentración inicial de $4 \mathrm{~g} / \mathrm{L}$ de oxalato de calcio, los aislados Serratia fonticola I, Bacillus subtilis II, Bacillus subtilis III, y Bacillus valismortis IV. El pH fue de 4.9, valor que presentó el suelo rizosférico de 0 . spiralis; para los aislados Bacillus valismortis V, Bacillus amyloliquefaciens VI y Bacillus cereus VII el pH fue de 5,4 valor del suelo de $O$. tuberosa y un control negativo (Alcanivorax sp.) (Tabla 3).

Tabla 3. Evaluación del pH de cada aislamiento cada 24 horas durante 96 horas

\begin{tabular}{|c|c|c|c|c|c|}
\hline \multirow[t]{2}{*}{ Aislados } & \multicolumn{5}{|c|}{ pH } \\
\hline & $\begin{array}{c}0 \\
\text { hora } \\
\text { s }\end{array}$ & $\begin{array}{c}24 \\
\text { horas }\end{array}$ & $\begin{array}{c}48 \\
\text { horas }\end{array}$ & $\begin{array}{c}72 \\
\text { horas }\end{array}$ & $\begin{array}{c}96 \\
\text { horas }\end{array}$ \\
\hline Serratia fonticola I & 4,90 & 5,75 & 6,00 & 6,00 & 6,10 \\
\hline Bacillus subtilis II & 4,90 & 5,98 & 6,22 & 6,22 & 6,24 \\
\hline Bacillus subtilis III & 4,90 & 5,80 & 5,90 & 5,90 & 5,90 \\
\hline $\begin{array}{l}\text { Bacillus } \\
\text { valismortis IV }\end{array}$ & 4,90 & 5,62 & 5,60 & 5,73 & 5,78 \\
\hline $\begin{array}{l}\text { Bacillus } \\
\text { valismortis } \mathrm{V}\end{array}$ & 5,40 & 6,13 & 6,55 & 6,55 & 6,60 \\
\hline $\begin{array}{l}\text { Bacillus } \\
\text { amyloliquefaciens } \\
\text { VI }\end{array}$ & 5,40 & 6,10 & 6,32 & 6,32 & 6,37 \\
\hline Bacillus cereus VII & 5,40 & 6,30 & 6,51 & 6,51 & 6,60 \\
\hline Alkanivorax sp & 4,90 & 4,90 & 4,90 & 4,90 & 4,90 \\
\hline Alkanivorax sp & 5,40 & 5,40 & 5,40 & 5,40 & 5,40 \\
\hline
\end{tabular}

Se observó un incremento del pH alrededor de las 24 horas en los 2 tratamientos, con valores entre 5,6 y 6,3 . A las 96 horas todos los tratamientos se estabilizaron entre 6,2 y 6,6. El efecto del pH sobre la actividad de degradación de oxalato al parecer es directo; cuando éste se va degradando, el $\mathrm{pH}$ aumenta de forma sustancial, a tal punto que se estabiliza, y cierta cantidad de oxalato queda remanente.

Con respecto a la degradación de oxalato, se observó un consumo significativo durante las primeras 48 horas, en las siguientes horas el oxalato degradado tuvo tendencia a ser constante. El aislado II presentó la máxima cantidad de oxalato degradado $2,9 \mathrm{~g} / \mathrm{L}$ y el aislado III degrado 
la menor cantidad de oxalato con un total de $1,04 \pm 0,04 \mathrm{~g} / \mathrm{L}$ (Tabla 4). El test de $\mathrm{T}$ indica que hay una diferencia estadísticamente significativa entre la media de los ensayos con respecto al control con un (valor de $\mathrm{p} \leq 0,005$ ).

Este reporte inicial puede tornarse en una alternativa para usar este tipo de bacterias en suelos con gran cantidad de oxalatos y debe ser tomado como un resultado indicativo para estudios futuros.

Tabla 4. Consumo de oxalato con respecto al tiempo

\begin{tabular}{lrrrrr}
\hline \multicolumn{1}{c}{ Especies } & \multicolumn{5}{c}{ Oxalato remanente (g/L) } \\
& 0 & \multicolumn{1}{c}{24} & \multicolumn{1}{c}{48} & \multicolumn{1}{c}{72} & \multicolumn{1}{c}{96} \\
& hora & horas & horas & horas & horas \\
& $\mathrm{s}$ & & & & \\
\hline Serratia fonticola & 4 & $2,22 \pm$ & $2,14 \pm$ & $2,07 \pm$ & $2,07 \pm$ \\
I & & 0,05 & 0,07 & 0,01 & 0,03 \\
Bacillus subtilis II & 4 & $2,00 \pm$ & $1,18 \pm$ & $1,10 \pm$ & $1,10 \pm$ \\
& & 0,10 & 0,30 & 0,04 & 0,00 \\
Bacillus subtilis & 4 & $3,70 \pm$ & $3,25 \pm$ & $2,96 \pm$ & $2,96 \pm$ \\
III & & 0,40 & 0,50 & 0,02 & 0,04 \\
Bacillus & 4 & $3,70 \pm$ & $2,22 \pm$ & $2,1 \pm$ & $2,14 \pm$ \\
valismortis IV & & 0,10 & 0,00 & 0,03 & 0,06 \\
Bacillus & 4 & $3,70 \pm$ & $3,37 \pm$ & $2,37 \pm$ & $2,22 \pm$ \\
valismortis V & & 0,20 & 0,09 & 0,08 & 0,03 \\
Bacillus & 4 & $2,96 \pm$ & $2,22 \pm$ & $2,22 \pm$ & $2,22 \pm$ \\
amyloliquefaciens & & 0,01 & 0,02 & 0,00 & 0,00 \\
VI & & & & & \\
Bacillus cereus & 4 & $2,96 \pm$ & $2,07 \pm$ & $2,07 \pm$ & $2,07 \pm$ \\
VII & & 0,03 & 0,00 & 0,00 & 0,00 \\
Alkanivorax sp & 4 & $3,78 \pm$ & $3,60 \pm$ & $3,5 \pm$ & $3,48 \pm$ \\
& & 0,02 & 0,01 & 0,0 & 0,04 \\
\hline
\end{tabular}

\section{Discusión}

El pH es determinante en la disponibilidad de bases intercambiables, puesto que a menor valor, los niveles de estos iones en el suelo bajan, debido a que los protones $\mathrm{H}^{+}$reemplaza a los de $\mathrm{Ca}^{2+}$, $\mathrm{Mg}^{2+} \mathrm{y} \mathrm{K}^{+}, 29$ por lo tanto, para suelos más ácidos como en 0 . spiralis, los valores de estos iones fueron menores $(5,75,0,81$ y 0,14 , respectivamente) en comparacion con 0 . tuberosa especie que presenta niveles más altos $(20,6,02$ y 2,49 ). Estos iones (bases intercambiables), se encuentran en mayor cantidad en suelos fértiles, así $O$. tuberosa podría encontrarse en un suelo más fértil que 0 . spiralis.

La acidificación de suelos es un indicador de especiación química y cambio de solubilidad en varias sustancias orgánicas e inorgánicas, situación que está relacionada con la alteración de procesos biológicos de síntesis como la fotosíntesis, la respiración o la disponibilidad de nutrientes esenciales $\left(\mathrm{NH}_{4}+, \mathrm{PO}_{4}^{-3}\right.$ y $\left.\mathrm{Mg}^{2+}\right)$, características que limitan el crecimiento de organismos vegetales o microorganismos, en este tipo de suelos.28

Los ácidos orgánicos actuan como agentes solubilizadores de compuestos que normalmente se encuentran insolubles.30 Para el caso del fosforo, los resutados indican que hay solubilización excesiva de este elemento, debido a que los valores de concentracion tienen un valor de $64,15 \mathrm{mg} / \mathrm{Kg}$ para O. spiralis y $36,08 \mathrm{mg} / \mathrm{Kg}$ para 0 . tuberosa, lo cual contrasta con lo reportado por Urbano et al.,31 quienes reportaron que los valores normales de fósforo estan entre 5 y $10 \mathrm{mg} / \mathrm{Kg}$.

Con respecto a la materia orgánica, se observó que los suelos de 0 . tuberosa y 0 . spiralis tienen un valor bastante alto de materia orgánica con 17,39 y $20 \%$ respectivamente, considerados suelos orgánicos. Así mismo, la concentración de nitrógeno para los dos suelos se incluye en la categoría alta debido a que fue mayor de 0,18\%.

Los metabolitos secundarios exudados por las plantas como el ácido oxálico proporcionan una fuente abundante de carbono y nitrógeno aprovechada por los microorganismos de la rizósfera, incrementando la materia orgánica presente en el suelo.32 La presencia de diferentes poblaciones bacterianas en la rizósfera de plantas del género Oxalis puede influir en varios aspectos: solubilidad de nutrientes como $\mathrm{P}, \mathrm{Fe}$, la modulación del ciclo de carbono lo que incrementaría la actividad oxalato-carbonato en el microsistema estudiado. Finalmente, se ha observado que pueden ser contribuyentes en la fertilidad del suelo y reciclaje de los elementos necesarios para el crecimiento vegetal como el K, Zn y Mo.15

La cantidad de ácido oxálico secretada al suelo está relacionada con las estructuras anatómicas de estas dos especies, como son sus tallos y raíces suculentas, como lo confirman Castillo et al.,23 
quienes cuantificaron el ácido oxálico en $O$. tuberosa y $O$. spiralis en mayor cantidad con respecto a otras espécies como $O$. mollis $O$. filiformis y 0. latifolia.

Los suelos de Chimayoy donde fue recolectada $O$. spiralis y de Catambuco 0 . tuberosa presentaron características fisicoquímicas muy similares, dentro de estos factores es importante resaltar la alta relación carbono: nitrógeno en los dos suelos muestreados 29:1 (Chimayoy) y 28:1 (Catambuco), la cual puede generar un estrés nutricional favorable para la acumulación de reservas de carbono por los microorganismos presentes en la microbiota de la rizósfera, y se recomienda un estudio complementario sobre la existencia de algún mecanismo de reserva como polihidroxialcanoatos en bacterias oxalotróficas provenientes de suelos andinos.

La relación entre la cantidad de oxalato degradado y el aumento del $\mathrm{pH}$ es evidente. Por ejemplo, se ha demostrado que en la bacteria Bacillus subtilis, la enzima oxalyl-CoA decarboxilasa encargada de la decarboxilación del ácido oxálico tiene una actividad óptima a un $\mathrm{pH}$ de 4.2. Curiosamente, estos resultados ilustran cómo analizar los efectos del pH sobre la actividad enzimática cuando los efectos del pH sobre los complejos enzimáticos alteran grupos ionizantes que participan en la catálisis, afectando las propiedades químicas y la estabilidad de la enzima, sustratos o cofactores.33

Por otra parte, estudios anteriores confirman que bacterias oxalotróficas asociadas a árboles en el continente Africano están relacionadas con la alcalinización de suelo y el consumo de oxalato.34 Es de resaltar que las especies bacterianas asociadas a las plantas Terminalia oblonga, en Bolivia, Terminalia berilica en India y Milicia excelsa en Camerún, presentan tasas de consumo de oxalato considerables y se destacan los géneros Variovorax sp., Lysobacter sp., Agrobacterium sp. y Bacillus sp., con una tasa de consumo menor.17 Es importante mencionar que los datos obtenidos en el estudio de Bravo y colaboradores fue por medio de microcalorimetría isotérmica (IMC) 22 y no es posible comparar con la metodología de reactantes y productos usada en el presente estudio, sin embargo sugerimos el uso de (IMC) para estudios futuros.

Desde el punto de vista ecológico los géneros encontrados en este estudio (Serratia y Bacillus) tienen bastante importancia en la naturaleza, ya que han sido aislados de diversos ambientes, como los rizosféricos, se recalca que la especie Bacillus valismortis IV aislada de $O$. spiralis, esta agrupada según el dendrograma bioquímico con las especies asociadas a 0 . tuberosa, lo que puede indicar que la rizosfera de estas especies vegetales ofrece condiciones ideales de crecimiento para las especies de Bacillus aisladas.16,35 Por otra parte, se ha demostrado que cepas de Bacillus amyloliquefaciens y Bacillus subtilis sintetizan sustancias promotoras del crecimiento vegetal, tales como giberelinas y ácido indol acético,36 enzimas del ácido fitíco (fitasas),37 quitinasa 38,39 y péptidos antifúngicos.40 La especie B. amyloliquefaciens ha sido asociada con la protección de plantas del género Brassica contra Leptoseriamaculans, fitopatógeno causante del carbunco sintomático.41

Se conoce que Serratia liquefaciens y Serratia proteamaculans producen promotores de crecimiento para las plantas, poseen propiedades antifúngicas, fomentan la fijación de nitrógeno y actúan como agentes patógenos de insectos.35 $\mathrm{Si}$ a esto le sumamos la capacidad de degradar oxalato, estas poblaciones bacterianas serán las encargadas de mantener los suelos en un buen estado, desarrollando una función importante en las interacciones planta-microorganismo.

La inoculación de este tipo de bacterias endofíticas puede dar lugar a la resistencia sistémica inducida en la planta hospedera, debido a que estas especies son en gran parte asociadas íntimamente con las raíces de plantas, y pueden ser utilizadas potencialmente en biofertilización y bioremediación de suelos por medio de la interacción planta- microorganismo.

Como fue mencionado anteriormente, los oxalatos sales del ácido oxálico son sustancias presentes en los alimentos de origen vegetal que, en dosis elevadas, pueden ser nocivas para la 
salud, ya que favorecen la formación de cálculos renales y pueden dificultar la función renal.

Se sabe, además, que aunque los oxalatos y el ácido úrico son sustancias diferentes, al actuar los dos sobre la función del riñón pueden tener un efecto sinérgico, y la presencia de uno puede agravar los problemas derivados del otro. Además, el ácido oxálico produce irritaciones locales importantes.5,7,9 La fácil absorción a través de las membranas mucosas y la piel causa trastornos en la circulación sanguínea, puede irritar el esófago y el estómago cuando se ingiere en altas cantidades, y causar daño renal (cálculos, oliguria, albuminuria, hematuria). Este ácido es letal en dosis altas, su precipitado (oxalato cálcico) puede ocasionar en algunos pacientes obstrucción renal, aparece en la orina de los animales y humanos en forma de oxalato de calcio y ácido oxalúrico $\left(\mathrm{H}_{2} \mathrm{~N}-\mathrm{CO}-\mathrm{NH}-\mathrm{CO}-\mathrm{CO}_{2} \mathrm{H}\right)$.

Las personas sanas pueden comer alimentos que contienen ácido oxálico u oxalatos, pero en pequeña cantidad, debido a su capacidad para unirse a ciertos minerales como el calcio, hierro, sodio, potasio o magnesio, el consumo de alimentos ricos en ácido oxálico puede causar deficiencias nutricionales, cuando el oxalato se une a los metales, imposibilitando la absorción de los microelementos en el cuerpo.

Este estudio a pesar de ser indicativo a nivel biológico, puede en un futuro y con base en mayores soportes en investigación, tornarse en una promisoria aplicación para reducir el oxalato de calcio en los alimentos de consumo diario, como es el caso de la espinaca, oca, patatas, zanahorias, coles, judías, remolacha, brócoli, etc, que presentan un renglón de importancia agrícola en la región.

El suministrar un medio propicio de inoculación biológica con las bacterias identificadas en este estudio como oxalotróficas, probablemente podrá disminuir el contenido de oxalato en los alimentos de consumo, mejorando el proceso de absorción de otros nutrientes y el estado nutricional de la población, gracias al rol importante que éstas desempeñan como sumidero de carbono a largo plazo, conversión geoestable de carbono proveniente de $\mathrm{CO}_{2}$ atmosférico y activación de la ruta oxalato-carbonato.17 No obstante, es muy claro que son indispensables más estudios enfocados al entendimiento del metabolismo microbiano, la repercusión en la carbonatogénesis in situ en los diversos nichos tropicales de diferentes regiones de Colombia y el mejoramiento de la bioconversión, con el fin de determinar su rol en la fijación de $\mathrm{CO}_{2}$ y su utilidad marcante en la región.

\section{Conclusiones}

Las especies identificadas como (Serratia fonticola, Bacillus amyloliquefaciens, Bacillus subtilis, Bacillus vallismortis y Bacillus cereus), se aislaron como parte de la microbiota natural de las plantas Oxalis spiralis y Oxalis tuberosa. Además enfatizamos que cumplen un papel importante en los suelos, debido a la capacidad de aumentar el pH cuando hay consumo de oxalato.

Las especies que presentaron mayor degradación de oxalato pueden ser estudiadas en trabajos complementares para evaluar su potencial como biofertilizantes y/o alternativas de bioremediación de suelos.

Este estudio a pesar de ser indicativo a nivel biológico, puede en un futuro y con base en mayores soportes en investigación, tornarse en una promisoria aplicación para reducir el oxalato de calcio en los alimentos de consumo diario.

\section{Agradecimientos}

Al Sistema de Investigaciones de la Universidad de Nariño (VIPRI), por la financiación de este proyecto.

Conflicto de intereses. Ninguno declarado por los autores.

\section{Referencias}

1. Stevenson FJ, Cole MA. Cycles of soil: carbon, nitrogen, phosphorus, sulfur, micronutrients. Cycles soil carbon, nitrogen, phosphorus, sulfur, Micronutr. 1999; 427 pp.

2. Haase S, Neumann G, Kania A, Kuzyakov Y, Römheld V, Kandeler E. Elevation of atmospheric $\mathrm{CO}_{2}$ and $\mathrm{N}$ - 
nutritional status modify nodulation, nodule-carbon supply, and root exudation of Phaseolus vulgaris L. Soil Biol Biochem. 2007;39(9):2208-21.

3. Suter D, Frehner M, Fischer BU, Nösberger J, Lüscher A. Elevated $\mathrm{CO}_{2}$ increases carbon allocation to the roots of Lolium perenne under free-air $\mathrm{CO}_{2}$ enrichment but not in a controlled environment. New Phytol. 2002;154(1):65-75.

4. Pendall E, Bridgham S, Hanson PJ, Hungate B, Kicklighter DW, Johnson DW, et al. Below-ground process responses to elevated $\mathrm{CO}_{2}$ and temperature: $\mathrm{A}$ discussion of observations, measurement methods, and models. New Phytol. 2004;162(2):311-22.

5. Cailleau G, Braissant O, Verrecchia EP. Biomineralization in plants as a long-term carbon sink. Naturwissenschaften. 2004;91(4):191-4.

6. Siener R, Hönow R, Seidler A, Voss S, Hesse A. Oxalate contents of species of the Polygonaceae, Amaranthaceae and Chenopodiaceae families. Food Chem. 2006;98(2):220-4.

7. Cailleau G, Braissant O, Verrecchia EP. Turning sunlight into stone: The oxalate-carbonate pathway in a tropical tree ecosystem. Biogeosciences. 2011;8(7):1755-67.

8. Nakata PA. Advances in our understanding of calcium oxalate crystal formation and function in plants. Plant Sci. 2003;164:901-9.

9. Yang JC, Loewus FA. Metabolic conversion of l-ascorbic acid to oxalic aAcid in oxalate-accumulating plants. Plant Physiol. 1975;56(2):283-5.

10. Albihn PB, Savage GP. The bioavailability of oxalate from Oca (Oxalis tuberosa). J Urol. 2001;166(2):420-2.

11. Lima VLAG De, Mélo EDA, Santos Lima L Dos. Physicochemical characteristics of Bilimbi (Averrhoa bilimbi L.). Rev Bras Frutic. 2001;23(2):421-3.

12. Dubois M, Savage GP, Martin RJ. The effect of cooking on the composition and colour of New Zealand grown oca. Food Chem. 2007;104(2):768-73.

13. Türkmen N. Oxalis Pes-Caprae F . Pleniflora (Lowe) Sunding (Oxalidaceae), A new record for the flora of Turkey. 2010;7(5):596-9.

14. Martin G, Guggiari M, Bravo D, Zopfi J, Cailleau G, Aragno M, et al. Fungi, bacteria and soil pH: The oxalatecarbonate pathway as a model for metabolic interaction. Environ Microbiol. 2012;14(11):2960-70.

15. Braissant O, Verrecchia EP, Aragno M. Is the contribution of bacteria to terrestrial carbon budget greatly underestimated? Naturwissenschaften. Springer; 2002;89(8):366-70.

16. Sahin N. Oxalotrophic bacteria. Research in Microbiology. 2003. p. 399-407.

17. Bravo D, Braissant O, Cailleau G, Verrecchia E, Junier P. Isolation and characterization of oxalotrophic bacteria from tropical soils. Arch Microbiol. 2014;197(1):65-77.

18. Oke OL. Oxalic acid in plants and in nutrition. World Rev Nutr Diet. ENGLAND; 1969;10:262-303.

19. Cala, Victoria, Kunimine Y. Distribución de plomo en suelos contaminados en el entorno de una planta de reciclaje de baterías ácidas. Rev Int Contam Ambient. 2003;19(3):109-15.

20. Bache BW. The Chemistry of Soils. Geol Mag. Cambridge Journals Online; 1990;127(02):190-1.
21. Bravo D, Cailleau G, Bindschedler S, Simon A, Job D, Verrecchia E, et al. Isolation of oxalotrophic bacteria able to disperse on fungal mycelium. FEMS Microbiol Lett. 2013;348:157-66.

22. Bravo D, Braissant O, Solokhina A, Clerc M, Daniels AU, Verrecchia $E$, et al. Use of an isothermal microcalorimetry assay to characterize microbial oxalotrophic activity. FEMS Microbiol Ecol. 2011;78(2):266-74.

23. Castillo, R., Hernandez, R., Patiño A., Perez J. Determinación de la producción de ácido oxálico en cinco especies de Oxalis y su relación con bacterias oxalotróficas asociadas a la rizósfera. VI Congreso Colombiano de Botánica 2011.

24. Somasegaran P, Hoben HJ. Methods In LegumeRhizobium Technology. Trop Agric. 1985;1-510.

25. Aragno, M, Schlegel $H$. The mesophilic hydrogenoxidizing (Knallgas) bacteria. The prokaryotes. A handbook on the biology of bacteria: Ecophysiology, isolation, identification, applications. 2nd editio. Balows, A., Trüper, H.G., Dworkin, M. Harder, W., Schleifer K-H, editor. New York: Springer-Verlag; 1992. 344-384 p.

26. Garrity G, Rainey FA, Widdel F. Bergey's Manual of Systematic Bacteriology. Bergey's Manual ${ }^{\circledR}$ of Systematic Bacteriology. 2005.

27. Blackmore MA, Quayle JR, Walker IO. Choice between autotrophy and heterotrophy in Pseudomonas oxalaticus. Utilization of oxalate by cells after adaptation from growth on formate to growth on oxalate. Biochem J. 1968;107(5):699-704.

28. Rozycki M, Bartha R. Problems associated with the use of azide as an inhibitor of microbial activity in soil. Applied and environmental microbiology. 1981. p. 833-6.

29. Brady NC, Weil RR. The nature and properties of soils. Macmillan Publishing CoNew York. 2002.960 p.

30. Aslim B, Caliskan F, Beyatli Y, Gunduz U. Poly- $\beta-$ hydroxybutyrate production by lactic acid bacteria. FEMS Microbiol Lett. 1998;159(2):293-7.

31. Urbano P. Tratado de fitotecnia Ggeneral. Edición 2a. Mundi-Prensa; 2001. 865 p.

32. Ludovic R. Plant and soil microbe interactions in controlled conditions: rhizosphere protozoa and bacterial community. University of Neuchâtel; 2008.

33. Svedružić D, Liu Y, Reinhardt LA, Wroclawska E, Cleland WW, Richards NGJ. Investigating the roles of putative active site residues in the oxalate decarboxylase from Bacillus subtilis. Arch Biochem Biophys. 2007;464(1):36-47.

34. Cailleau G, Mota M, Bindschedler S, Junier P, Verrecchia EP. Detection of active oxalate-carbonate pathway ecosystems in the Amazon Basin: Global implications of a natural potential C sink. Catena. 2014;116:132-41.

35. Grimont PAD, Grimont F, Starr MP. Serratia species isolated from plants. Current Microbiology. 1981. p. 317-22.

36. Turner JT, Backman PA. Factors relating to peanut yield increases after seed treatment with Bacillus subtilis. Plant Dis. 1991;75(4):347-53. 
37. Idriss EE, Makarewicz O, Farouk A, Rosner K, Greiner R, Bochow $\mathrm{H}$, et al. Extracellular phytase activity of Bacillus amyloliquefaciens FZB45 contributes to its plant-growth-promoting effect. Microbiology. 2002;148(7):2097-109.

38. Manjula K, Podile AR. Chitin-supplemented formulations improve biocontrol and plant growth promoting efficiency of Bacillus subtilis AF 1. Can J Microbiol. 2001;47(7):618-25.

39. Chang WT, Chen CS, Wang SL. An antifungal chitinase produced by Bacillus cereus with shrimp and crab shell powder as a carbon source. Curr Microbiol. 2003;47(2):102-8.

40. Walker R, Powell AA, Seddon B. Bacillus isolates from the spermosphere of peas and dwarf French beans with antifungal activity against Botrytis cinerea and Pythium species. J Appl Microbiol. 1998;84(5):791-801.

41. Reva ON, Dixelius C, Meijer J, Priest FG. Taxonomic characterization and plant colonizing abilities of some bacteria related to Bacillus amyloliquefaciens and Bacillus subtilis. FEMS Microbiol Ecol. 2004;48(2):24959. 